\title{
Investigating the Association Between Serum Vitamin D Deficiency and Idiopathic Benign Paroxysmal Positional Vertigo
}

\author{
Jignesh Dhirubhai Dhameliya ${ }^{1 \oplus}$, Umesh Kumar Chandra ${ }^{2}{ }^{\circledR}$, Sumit Kumar Vishwakarma ${ }^{2}$, Dattaprasad \\ Ganganpallii $^{(0)}$, Archana Verma ${ }^{2 *}$
}

'Department of Neurology, Choithram Hospital \& Research Centre, Indore, MP, India

${ }^{2}$ Department of Medicine, MGM Medical College and MY Hospital, Indore, MP, India

\begin{abstract}
Background: It is suggested that there is a positive association between vitamin D deficiency and benign paroxysmal positional vertigo (BPPV). We suggest, as a hypothesis, there is a positive association between vitamin D deficiency and BPPV. The current study aimed to investigate the association between vitamin D levels and BPPV.

Methods: The present observational case-control study was planned and conducted on 100 participants (50 cases and 50 controls) in the Department of Neurology, Choithram Hospital \& Research Center (CHRC), Indore, MP, India, from January 2018 to December 2018. All consecutive patients with diagnosis of idiopathic BPPV who were above the age of 18 years with a negative neurological status were included. Analyses were performed using SPSS software version 10.

Results: BPPV was more common among those aged 50 to 70 years (64\%). Out of 100 participants, $72(72 \%)$ had vitamin D deficiency, in which $40(80 \%)$ were cases and $32(64 \%)$ were controls. $32(64 \%)$ patients had posterior canal involved, out of them $20(40 \%)$ were females and $12(24 \%)$ were males, and in both groups posterior canal was more involved. Canal involvement according to gender was not statistically significant $(P$ value $=0.45)$. Mean vitamin $\mathrm{D}$ level for cases and controls was 34.9 and $46.5 \mathrm{nmol} / \mathrm{L}$, respectively, and this difference was statically very significant with a p-value of $0.01(P$ value $<0.05)$

Conclusion: According to the findings, there is a statistically significant association between vitamin D3 deficiency and Idiopathic BPPV. It can be noted that vitamin D3 deficiency may be a risk factor for the BPPV.

Keywords: Benign positional paroxysmal vertigo; Posterior canal; Vitamin D deficiency
\end{abstract}

*Correspondence to

Dr. Archana Verma, MD, DNB Neurology, Associate Professor Division of Neurology,

Department of Medicine, MGM Medical College and MY Hospital Indore, MP, India. Contact: 11/2, Narayan Bagh, Indore, MP, India, 452001. Email: archv1234@yahoo.com

Published online June 21, 2020

Citation: Dhameliya JD, Chandra UK, Vishwakarma SK, Ganganpalli D, Verma A. Investigating the Association Between Serum Vitamin D Deficiency and Idiopathic Benign Paroxysmal Positional Vertigo. Clin Neurosci J. 2020;7(3):122-126. doi:10.34172/icnj.2020.12.

\section{Introduction}

Benign paroxysmal positional vertigo (BPPV) is a recurrent vestibular disorder characterized by rotator attacks lasting for a few seconds, which can be elicited by particular head movements. BPPV is the most common cause of vestibular disorder that accounts for approximately $20 \%-30 \%$ of all vertigo cases. ${ }^{1}$ One-year prevalence of the BPPV in a group of individuals aged more than 60 years old was about seven times higher than those aged 18 to 39 years. $^{2}$

Most cases are idiopathic and secondary BPPV accounts for approximately $10 \%$ of cases. ${ }^{3}$ BPPV can be caused by either canalithiasis or cupulolithiasis and affects any of the three semicircular canals. In most cases, the posterior canal affects. ${ }^{4}$ Patient's history, clinical examination, and specific clinical tests that expose each semicircular canal to gravity force and causing positional nystagmus, are the most common ways to diagnosis the BPPV. ${ }^{5}$

According to the previous studies, the absence of vestibular vitamin $D$ receptor in mice results in vestibular dysfunctions. ${ }^{6}$ Patients with BPPV have lower bone mineral density. Based on the afro-mentioned, it is hypothesized that low serum vitamin D3 levels can cause BPPV in humans.?

Serum calcium and serum vitamin D3 levels play an important role in improving bone mineral density and reducing the risk of bone fractures. ${ }^{8}$ Low levels of serum vitamin D3 are associated with low bone mass. It is well known that vitamin D3 supplementation reduces the risk of fractures in elders. In mice, vitamin $\mathrm{D}$ receptor deficiency is associated with balance impairment. Similarly, vitamin D deficiency may also predispose

(C) 2020 The Author(s). This is an open access article distributed under the terms of the Creative Commons Attribution License (http:// creativecommons.org/licenses/by/4.0/), which permits unrestricted use, distribution, and reproduction in any medium, provided the original work is properly cited. 
humans to impaired balance/posture controls. Vitamin D is necessary for calcium absorption and bone hemostasis, so there is an association between biomarkers of bone turn over and the BPPV. ${ }^{9}$

Based on what mentioned before, it is suggested that there is an association between serum vitamin D3 levels and the incidence of BPPV. The current study aimed to investigate the association between vitamin D3 deficiency and incidence of BPPV.

\section{Materials and Methods}

The current single centre observational case-control study was planned and conducted in the Department of Neurology, Choithram Hospital \& Research Center (CHRC), Indore, MP, India, from January 2018 to December 2018. The patients presented at Outpatient Department (OPD) or admitted to the Department of Neurology, CHRC, were included in the study after obtaining informed written consent. Similar age group and sex-matched hospital-based controls were included in the study for comparison with cases.

All BPPV patients presenting to the OPD or emergency department or admitted in the wards of the Department of Neurology were subjected to a detailed history taking, thorough clinical examination, and investigations as per working proforma. All patients were under-go detailed evaluation for spontaneous nystagmus, head-shaking nystagmus, and positional nystagmus in addition to routine neurological examination.

Inclusion criteria were defined as all consecutive patients with the diagnosis of idiopathic BPPV who were above the age of 18 with negative neurological status presented at the above mentioned centre from January 2018 to December 2018 were included.

Exclusion criteria were as follows:

1. History of head and ear trauma, surgery or infectious diseases of the ear, maxillary sinuses, and neck areas during the preceding month of BPPV attack.

2. Patients with chronic renal, pulmonary, hematologic, gastrointestinal, cardiovascular diseases.

3. Taking supplementary calcium and vitamin D or taking medications that alter vitamin D metabolism (in the last 1 year).

4. Patients with a history or active case of inner ear diseases.

5. Patients with a typical history of BPPV without exhibit nystagmus on clinical tests.

6. Patients whose data is incomplete or denied for consent may be excluded.

Diagnosis of BPPV was based on the following criteria ${ }^{10}$ :

A. Recurrent rotator attacks of positional vertigo or vertigo provocation during the posture change.

B. Duration of rotator attacks less than 1 minute.

C. Positional nystagmus of clinical maneuvers.

D. Nystagmus not attributable to any other disorder.
To measure serum vitamin D3 levels, fasting morning venous blood sample was collected from all participants. The serum level of vitamin D3 was measured using The ARCHITECT STAT i1000SR immunoassay analyzer by the chemiluminescent microparticle immunoassay (CMIA) method. The following categorization was used for the vitamin D3 levels: normal (more than $75 \mathrm{nmol} / \mathrm{L}$ or $30 \mathrm{ng} / \mathrm{mL}$ ); insufficient (50 to $74 \mathrm{nmol} / \mathrm{L}$ or 21 to 29 $\mathrm{ng} / \mathrm{mL}$ ); and deficient (less than $50 \mathrm{nmol} / \mathrm{L}$ or $20 \mathrm{ng} / \mathrm{mL}$ ). The study had not interfered with the ongoing treatment of the patients.

\section{Statistical Analysis}

The sample size was calculated with OpenEPI software by using the Kelsey et al method, which indicated a sample size of 78 (i.e. 39 for the case and 39 for the control groups) (Odd ratio 3.80, ratio of case and control $=1: 1$ and power $=80 \%)$. Eventually, a total of 100 participants were sampled (50 for each group). Fifty cases that presented to the hospital with idiopathic BPPV diagnosis were included after applying inclusion criteria, and 50 control subjects were chosen from age and sex-matched patients without BPPV who attended the neurology OPD or other healthy persons who come for medical check-up or hospital staffs agreed to participate in the current study. Data were analyzed using SPSS software. $\chi^{2}$ test was used for categorical variables. Student t-test was used for the unpaired parametric data. The ANOVA test was used for $>2$ groups parametric data. The Mann Whitney U test was applied for continuous variables. The Kruskal-Wallis test was applied to compare variables when more than 2 groups were available for non-parametric data. Pearson's correlation equation and Spearman's Rho method were used in accordance with the variables group.

\section{Results}

The current clinical study was conducted at CHRC, Indore, MP, India, from January 2018 to December 2018. In total 100 patients were participated (50 in each group). Data were collected using a questionnaire.

The prevalence of BPPV was higher among those aged 50 to 70 years $(64 \%)$. Most of the patients with BPPV were females (60\%). Out of 50 patients, the prevalence of posterior canal, lateral canal, and anterior canal involvement were 32 (64\%), 17 (34\%), and 1 (2\%), respectively. Right and left side involvement was found in $28(56 \%)$ and 22(44\%) patients, respectively (Table 1 ).

$72(72 \%)$ participants had vitamin D deficiency (40\% in the case group and $32 \%$ in the controls group). The difference between both groups was statistically significant $(P$ value $=0.03)($ Table 2$)$. The mean age of females was higher than males, and mean vitamin D levels were higher in males in comparison to females, but the difference was not statistically significant $(P$ value $=0.05)($ Table 3$)$.

$32(64 \%)$ patients had posterior canal involved, that 20 
Table 1. Demographic and Clinical Characteristics of Cases and Controls

\begin{tabular}{lcc}
\hline Characteristics & Cases (\%) & Controls (\%) \\
\hline Age $(\mathrm{y})$ & $6(12 \%)$ & $6(12 \%)$ \\
$<40$ & $8(16 \%)$ & $8(16 \%)$ \\
$41-50$ & $16(32 \%)$ & $16(32 \%)$ \\
$51-60$ & $16(32 \%)$ & $16(32 \%)$ \\
$61-70$ & $4(8 \%)$ & $4(8 \%)$ \\
$>70$ & & $30(60 \%)$ \\
Gender & $30(60 \%)$ & $20(40 \%)$ \\
Female & $20(40 \%)$ & \\
Male & & $\mathrm{NA}$ \\
Site & $22(44 \%)$ & $\mathrm{NA}$ \\
Left & $28(56 \%)$ & $\mathrm{NA}$ \\
Right & & $\mathrm{NA}$ \\
Canal involvement & $17(34 \%)$ & $\mathrm{NA}$ \\
Posterior & & \\
Lateral & & \\
Anterior & & \\
\hline NA & &
\end{tabular}

NA, not available.

Table 2. Correlation Between Vitamin D Deficiency With BPPV

\begin{tabular}{lcccc}
\hline \multirow{2}{*}{$\begin{array}{l}\text { Vitamin D } \\
\text { deficiency }\end{array}$} & \multicolumn{2}{c}{ Study Group } & \multirow{2}{*}{ Total } & $\boldsymbol{P}_{\text {value }}{ }^{\mathrm{a}}$ \\
\cline { 2 - 3 } & Cases & Controls & & \\
\hline Yes & $40(40 \%)$ & $32(32 \%)$ & $72(72 \%)$ & \\
No & $10(10 \%)$ & $18(18 \%)$ & $28(28 \%)$ & 0.03 \\
Total & $50(50 \%)$ & $50(50 \%)$ & $100(100 \%)$ & \\
\hline
\end{tabular}

a Mann-Whitney $U$ test.

Table 3. Correlation Between Mean Age, Vitamin D Level, and Gender

\begin{tabular}{lcccc}
\hline Characteristics & Variable & Male & Female & P Value $^{\mathbf{a}}$ \\
\hline Age, mean (SD) & Cases & $\begin{array}{c}57.3 \\
(13.8)\end{array}$ & $\begin{array}{c}58.5(9.6) \\
34.7\end{array}$ & 0.7 \\
Vit D level (nmol/L), Mean (SD) & Cases & $\begin{array}{c}34.9 \\
(16.3)\end{array}$ & $\begin{array}{c}3 \\
(13.4)\end{array}$ & 0.9 \\
\hline
\end{tabular}

(40\%) of them were females and $12(24 \%)$ were males. Besides, in both groups, the posterior canal was more involved. But canal involvement according to gender was not statistically significant ( $P$ value is $>0.05$ ). Left and right sides were affected in $22(44 \%)$ and 28 (56\%) of patients. Overall, the prevalence of left side involvement was higher among females, and right side involvement was more common among males. There was no significant difference based on gender $(P$ value $<0.05)$ (Table 4 ).

The mean age of participants in the case and control groups was 57.8 and 57.3 years, respectively. Mean duration of symptoms was 3.9 days. The mean vitamin D level for case and control groups was 34.9 and 46.5 $\mathrm{nmol} / \mathrm{L}$, respectively, and the difference was statically very significant $(\mathrm{p}$-value $=0.01$ ). The Mean value of serum calcium levels, phosphorus, alkaline phosphatase, \& serum parathormone were almost similar in both groups, and the difference was not statistically significant $(P$ value $>0.05$ ) (Table 5).

\section{Discussion}

Most BPPV cases are idiopathic. Previous studies showed that bone mineral density is lower among BPPV patients. Many studies mentioned the association between vitamin D3 and low bone mass. Given this statement, we conducted the current study to investigate the association between idiopathic BPPV and vitamin D level.

BPPV was found to be more common in those aged 51 to 70 years (64\%). Patients' age ranged from 36 to 90 years, and for the control group, it ranged from 34 to 90 years. The mean age for the case and control groups was $57.8( \pm 12.2)$ and $57.3( \pm 12.2)$ years, respectively. In cases, the female age $(58.5 \pm 9.6$ years $)$ was slightly higher than males ( $57.42 \pm 13.8$ years), but the difference was not statistically significant. Karataş et al reported that a mean age of 51.4 years for BPPV patients, which is consistent with the findings of the current study. ${ }^{11}$ Talaat et al also reported a mean age of $47.6 \pm 9.1$ years. They also found that the mean age of recurrent subjects (i.e. $48.3[ \pm 9.4]$ years) was higher than non-recurrent subjects $47( \pm 8.9)$, which is in line with the current study. ${ }^{12}$

In the case group, females (60\%) were more affected than males $(40 \%)$. In $64 \%$ of the patients, the posterior canal was affected ( $24 \%$ male and $40 \%$ female). Hence, in both groups, posterior canal was more involved. Among

Table 4. Gender Distribution With Reference to Canal and Site Involvement

\begin{tabular}{lccccc}
\hline \multirow{2}{*}{ Gender } & \multicolumn{3}{c}{ Canal involvement } & \multirow{2}{*}{ Total } & P Value \\
\cline { 2 - 4 } & Posterior & Lateral & Anterior & & \\
\hline Male & $12(24 \%)$ & $7(14 \%)$ & $1(2 \%)$ & $20(40 \%)$ & \\
Female & $20(40 \%)$ & $10(20 \%)$ & $0(0 \%)$ & $30(60 \%)$ & 0.45 \\
Total & $32(64 \%)$ & $17(34 \%)$ & $1(2 \%)$ & 50 & \\
\hline \multicolumn{5}{c}{ Site involvement } \\
\cline { 2 - 4 } Memale & $16(12 \%)$ & $14(28 \%)$ & & \\
Total & $22(44 \%)$ & $14(28 \%)$ & $30(60 \%)$ & 0.05 \\
\hline
\end{tabular}

Table 5. Correlation of Mean Age, Duration, Vitamin D3 Level, Calcium, Phosphorus, ALP, and PTH Level in Between Cases and Controls

\begin{tabular}{lccc}
\hline Characteristics & Cases & Controls & $P$ Value \\
\hline Age (y), mean (SD) & $57.8(12.2)$ & $57.3(12.2)$ & 0.8 \\
Duration of symptom in days, mean (SD) & $3.9(3.1)$ & $\mathrm{NA}$ & \\
Vitamin D3 (nmol/L), mean (SD) & $34.9(15)$ & $46.5(27.5)$ & 0.01 \\
S. $\mathrm{Ca}^{2+}$, mean (SD) & $9.2(0.6)$ & $9.2(0.6)$ & 0.99 \\
Phosphorus, mean (SD) & $3.5(0.4)$ & $3.4(0.3)$ & 0.1 \\
ALP, mean (SD) & $84.8(18.5)$ & $88.92(16.4)$ & 0.2 \\
PTH, mean (SD) & $31.5(7.1)$ & $30.7(6.6)$ & 0.5 \\
\hline
\end{tabular}

ALP, alkaline phosphatase, PTH, parathyroid hormone. 
females, left side (32\%) was more affected than the right side $(28 \%)$, while in male patient's right side $(28 \%)$ was more affected as compared to the left side (12\%), and the difference was statistically significant $(P$ value $=0.05)$.

Talaat et al reported a higher percentage of females (65\%) than males (35\%), which is consistent with the current study. Rhim found that $72.85 \%$ were females and $27.15 \%$ were males, which is comparable with the results of the current study. ${ }^{13}$ Yetiser and Ince reported that the prevalence of BPPV was 1.5 times higher among women. ${ }^{14}$

In the current study, the highest impact was for the posterior canal followed by lateral canal, and the least affect was for the anterior canal. Jeong et al reported that the highest and lowest impacts were on the posterior canal (in 51\% cases) and anterior canal. ${ }^{7}$ Katsarkas et al also found that BPPV of the posterior semicircular canal was more common than the horizontal semicircular canal. ${ }^{15}$ The current and previous studies suggested that the posterior Semi-circular canal was more involved, because it was more susceptible to gravity.

The right ear was more affected in the current study, which is comparable to the study conducted by von Brevern et $\mathrm{al}^{16}$ that reported more involvement of the right ear, due to sleeping in the right lateral decubitus position. Katsarkas et $\mathrm{al}^{15}$ reported $57.74 \%$ and $42.26 \%$ involvements for the right and left sides, respectively.

The mean value of vitamin $\mathrm{D}$ for case and control groups was $34.9( \pm 15)$ and $46.5( \pm 27.5) \mathrm{nmol} / \mathrm{L}$, respectively. The prevalence of vitamin D deficiency was $72 \%$ in the current study (40\% for cases and 32\% for controls).

Jeong et al found that serum level of vitamin D3 was lower in BPPV patients $(14.4 \pm 8.4)$, both in male $(16.2 \pm 8.9)$ and female $(13.4 \pm 8.0)$. Han et al also found that on post- menopausal women the mean serum vitamin D3 levels were significantly lower in patients with primary BPPV than controls $(19.1 \pm 5.2$ versus $22.5 \pm 5.8$, $P$ value $<0.001) .{ }^{17}$

Sen et al reported that mean serum vitamin D3 levels in patients with BPPV and healthy controls were $20.3 \pm 12.2$ and $18 \pm 10.1 \mathrm{ng} / \mathrm{mL}$, respectively. The prevalence of vitamin D3 deficiency among the BPPV patients and controls was $76 \%$ and $42 \%$, respectively. A statistically significant difference was observed in the mean serum vitamin D3 levels and the deficiency prevalence between the two groups. ${ }^{18}$

$\mathrm{Ca}^{2+}$ and carbonate ions are of crucial importance for vertebrate otoconia production. Besides, $\mathrm{Ca}^{2+}$ is required to mineralize otoconia and to maintain any turnover in the otolith, because the otoconia has a dynamic state. ${ }^{19,20}$ Sanyelbhaa and Sanyelbhaa noted that vitamin D3 deficiency leads to the formation of abnormal otoconia in the inner ear, which results in otolith dysfunction of the inner ear. ${ }^{21}$

Dynamic calcium uptake also causes otolith of utricle in the inner ear, and this process is well related to calcium- binding proteins that are up-regulated by vitamin $\mathrm{D} 3 .^{22}$ Vestibular dysfunction is observed in mice without the vestibular D3 receptor. It has been assumed that serum vitamin D3 deficiency leads to BPPV via deranged calcium metabolism in the vestibular organs of the inner ear. $^{23}$

Decreased fixation of calcium may cause failures in the remodeling of the internal structures of the otoconia in the inner ear. ${ }^{24}$ This is consistent with a recent report that noted to significant and inverse association between serum vitamin D3 and markers of bone metabolism. The reported also noted that vitamin D3 supplementation may prevent and treat BPPV recurrences. ${ }^{25}$ We have posited that Vitamin D prophylaxis may prevent development of the idiopathic BPPV. Further studies are needed to demonstrate this clinical significance.

Finally, the condition of forming abnormal otoconia as a result of deranged calcium metabolism may prepare the ground for the disease. We suggest that BPPV may be a sequel of low vitamin $\mathrm{D}$ and disturbed calcium homeostasis. In conclusion, there seems to be a positive association between BPPV and low serum levels of vitamin D3. Although it is thought that serum vitamin D3 deficiency could play a major role in the pathogenesis of BPPV, meanwhile it could also be a trigger factor.

\section{Conclusion}

According to the findings of the current study, it can be concluded that there is a statistically significant association between serum vitamin D3 deficiency and idiopathic BPPV. Moreover, it can be considered that serum vitamin D3 deficiency may be a risk factor for the BPPV. Further studies, such as large randomized control trials or large case-control studies are advised to confirm or exclude the above findings.

\section{Conflict of Interest}

None.

\section{Ethical Statement}

The study was approved by the Institutional Ethics Committee (Code: EC/JUN/1914).

\section{References}

1. Gámiz MJ, Lopez-Escamez JA. Health-related quality of life in patients over sixty years old with benign paroxysmal positional vertigo. Gerontology. 2004;50(2):82-6. doi: 10.1159/000075558.

2. von Brevern $M$, Radtke $A$, Lezius F, Feldmann M, Ziese $\mathrm{T}$, Lempert $\mathrm{T}$, et al. Epidemiology of benign paroxysmal positional vertigo: a population based study. J Neurol Neurosurg Psychiatry. 2007;78(7):710-5. doi: 10.1136/ jnnp.2006.100420.

3. Hilton MP, Pinder DK. The Epley (canalith repositioning) manoeuvre for benign paroxysmal positional vertigo. Cochrane Database Syst Rev. 2014(12):CD003162. doi: 10.1002/14651858.CD003162.pub3.

4. Parnes LS, Agrawal SK, Atlas J. Diagnosis and management 
of benign paroxysmal positional vertigo (BPPV). CMAJ. 2003;169(7):681-93.

5. Pérez-Vázquez P, Franco-Gutiérrez V. Treatment of benign paroxysmal positional vertigo. A clinical review. J Otol. 2017;12(4):165-73. doi: 10.1016/j.joto.2017.08.004.

6. Minasyan A, Keisala T, Zou J, Zhang Y, Toppila E, Syvälä H, et al. Vestibular dysfunction in vitamin $D$ receptor mutant mice. J Steroid Biochem Mol Biol. 2009;114(3-5):161-6. doi: 10.1016/j.jsbmb.2009.01.020.

7. Jeong SH, Kim JS, Shin JW, Kim S, Lee H, Lee AY, et al. Decreased serum vitamin $D$ in idiopathic benign paroxysmal positional vertigo. J Neurol. 2013;260(3):832-8. doi: 10.1007/ s00415-012-6712-2.

8. Ahmadieh H, Arabi A. Vitamins and bone health: beyond calcium and vitamin D. Nutr Rev. 2011;69(10):584-98. doi: 10.1111/j.1753-4887.2011.00372.x.

9. Dhesi JK, Jackson SH, Bearne LM, Moniz C, Hurley MV, Swift CG, et al. Vitamin D supplementation improves neuromuscular function in older people who fall. Age Ageing. 2004;33(6):589-95. doi: 10.1093/ageing/afh209.

10. von Brevern M, Bertholon P, Brandt T, Fife T, Imai T, Nuti D, et al. Benign paroxysmal positional vertigo: Diagnostic criteria. J Vestib Res. 2015;25(3-4):105-17. doi: 10.3233/ves-150553.

11. Karataş A, Acar Yüceant G, Yüce T, Hacı C, Cebi IT, Salviz M. Association of benign paroxysmal positional vertigo with osteoporosis and vitamin D deficiency: a case controlled study. J Int Adv Otol. 2017;13(2):259-65. doi: 10.5152/ iao.2016.2640

12. Talaat HS, Abuhadied G, Talaat AS, Abdelaal MS. Low bone mineral density and vitamin $\mathrm{D}$ deficiency in patients with benign positional paroxysmal vertigo. Eur Arch Otorhinolaryngol. 2015;272(9):2249-53. doi: 10.1007/ s00405-014-3175-3.

13. Rhim Gl. Serum vitamin D and recurrent benign paroxysmal positional vertigo. Laryngoscope Investig Otolaryngol. 2016;1(6):150-3. doi: 10.1002/lio2.35.

14. Yetiser $S$, Ince D. Demographic analysis of benign paroxysmal positional vertigo as a common public health problem. Ann Med Health Sci Res. 2015;5(1):50-3. doi: 10.4103/21419248.149788 .
15. Katsarkas A. Benign paroxysmal positional vertigo (BPPV): idiopathic versus post-traumatic. Acta Otolaryngol. 1999;119(7):745-9. doi: 10.1080/00016489950180360.

16. von Brevern $M$, Seelig $T$, Neuhauser $H$, Lempert $T$. Benign paroxysmal positional vertigo predominantly affects the right labyrinth. J Neurol Neurosurg Psychiatry. 2004;75(10):14878. doi: 10.1136/jnnp.2003.031500.

17. Han W, Fan Z, Zhou M, Guo X, Yan W, Lu X, et al. Low 25-hydroxyvitamin $D$ levels in postmenopausal female patients with benign paroxysmal positional vertigo. Acta Otolaryngol. 2018;138(5):443-6. doi: 10.1080/00016489.2017.1416168.

18. Sen K, Padiyar BV, Arora G. Association of benign paroxysmal positional vertigo with osteoporosis and vitamin D deficiency - a case-control study. Dubai Med J. 2018;1:2-5. doi: 10.1159/000492756.

19. Preston RE, Johnsson LG, Hill JH, Schacht J. Incorporation of radioactive calcium into otolithic membranes and middle ear ossicles of the gerbil. Acta Otolaryngol. 1975;80(3-4):269-75. doi: 10.3109/00016487509121327.

20. Ross MD. Calcium ion uptake and exchange in otoconia. Adv Otorhinolaryngol. 1979;25:26-33. doi: 10.1159/000402913.

21. Sanyelbhaa H, Sanyelbhaa A. Vestibular-evoked myogenic potentials and subjective visual vertical testing in patients with vitamin D deficiency/insufficiency. Eur Arch Otorhinolaryngol. 2015;272(11):3233-9. doi: 10.1007/s00405-014-3395-6.

22. Thalmann R, Ignatova E, Kachar B, Ornitz DM, Thalmann I. Development and maintenance of otoconia: biochemical considerations. Ann N Y Acad Sci. 2001;942:162-78. doi: 10.1111/j.1749-6632.2001.tb03743.x.

23. Vibert D, Kompis M, Häusler R. Benign paroxysmal positional vertigo in older women may be related to osteoporosis and osteopenia. Ann Otol Rhinol Laryngol. 2003;112(10):885-9. doi: 10.1177/000348940311201010.

24. Vibert D, Sans A, Kompis M, Travo C, Muhlbauer RC, Tschudi I, et al. Ultrastructural changes in otoconia of osteoporotic rats. Audiol Neurootol. 2008;13(5):293-301. doi: 10.1159/000124277.

25. Büki B, Ecker M, Jünger H, Lundberg YW. Vitamin D deficiency and benign paroxysmal positioning vertigo. Med Hypotheses. 2013;80(2):201-4. doi: 10.1016/j.mehy.2012.11.029. 